\title{
Dissolution Effect of Gastric and Intestinal pH fora BCS class II drug, Pioglitazone: New in vitro Dissolution System to Predict in vivo Dissolution
}

\author{
Yasuhiro Tsume*, Gordon L Amidon and Susumu Takeuchi
}

University of Michigan, Ann Arbor, MI 48109, USA

Keywords: Dissolution; In vitro; Gastric pH; Intestinal pH; ASD; GIS Introduction

The U.S. Food and Drug Administration (FDA) released guidelines based on the Biopharmaceutics Classification System (BCS), which classifies drugs into 4 groups,for the pharmaceutical industry in 2000 [1]. The European Medicines Agency (EMA) and FDA have released guidances for the bioequivalence $(\mathrm{BE})$ and the requirements of the $\mathrm{BCS}$ based biowaiver for immediate release (IR) drug products in BCS class I $[1,2]$. The expansion ofbiowavers to some BCS class II drugs has been evaluated; particularly weak acidic drugs such as ibuprofen, ketoprofen and naproxen, are potential candidates for biowaivers [3]. These drugs, which are highly permeable, can dissolve quickly at intestinal $\mathrm{pH}$ (6.57.0) and, therefore, behave like BCS class I drugs in the intestinal tract, even though they exhibit low solubility at acidic $\mathrm{pH}$ [4-6]. However, Alvarez and coworkers have been reported that it would be risky to biowaiver BCS class II acidic drugs using just in vitro dissolution tests [7]. On the other hand, BCS class II weak basic drugs such as ketoconazole, dipyridamole, and carvedilol, easily dissolve in gastric $\mathrm{pH}$ and then may occur the precipitation or reach the supersaturation entering the duodenum due to higher environmental $\mathrm{pH}[8,9]$. Even the limited solubility in intestinal $\mathrm{pH}$, almost complete oral absorption of BCS class II drugslike ketoconazole,carvedilol, and pioglitazone, which dissolve in acidic $\mathrm{pH}$ but less dissolve in intestinal $\mathrm{pH}$, has been reported [10-13]. The in vitro dissolution study with the USP apparatus II (paddle), which is a golden standard for in vitrodissolution study, for thosedrugs would not allow the observation ofprecipitation and supersaturation of those test drugs. Taken together, those reports and concerns raise questions of currentin vitro dissolution systems and of the discrepancyof in vitro- in vivo dissolution. The development of new biopredictive dissolution systems, which emulates in vivo condition, would be required to predict the dynamicin vivo dissolution effects. Thus, new dissolution systems and techniques such as artificial stomach-duodenal (ASD) model and two-phase testing dissolution systems have been developed and assessed for their feasibilities and reliabilities to predict in vivo phenomena[14-19]. Those in vitro dissolution systems predict in vivo dissolution more accurately for BCS class II drugs than USP dissolution systems, indicating that the current in vitro dissolution systems may not be good enough to predict in vivo dissolution.

In this article, the new dissolution apparatus called gastro intestinal simulator (GIS) is constructed with three compartments to predict in vivo drug dissolution and to monitor the change of drug concentration in each compartment. This system would help to understand the drug dissolution stimulating in vivo environment and the transit of drug solution along with GI tract.We examine the dissolution profile of a BCS class II drug, pioglitazone, using the GIS and the feasibility of dissolution result by the GIS to predict in vivo dissolution ofpioglitazone.

\section{Experimental}

\section{Materials}

Pioglitazone tablets were obtained from Takeda Pharmaceutical (Osaka, Japan). High-performanceliquid chromatography (HPLC) grade acetonitrile was obtainedfrom Fisher Scientific (St. Louis, MO). Trifluoroacetic acid (TFA), and allother reagents and solvents were purchased from Aldrich ChemicalCo. (Milwaukee, WI).All chemicals were either analytical or HPLC grade.

\section{GIS apparatus}

The in vitro GIS model consists of three dissolution chambers representing the stomach, duodenum, and early jejunum with $\mathrm{pH}$ monitoring system in each chamber (Figure 1). The stomach and

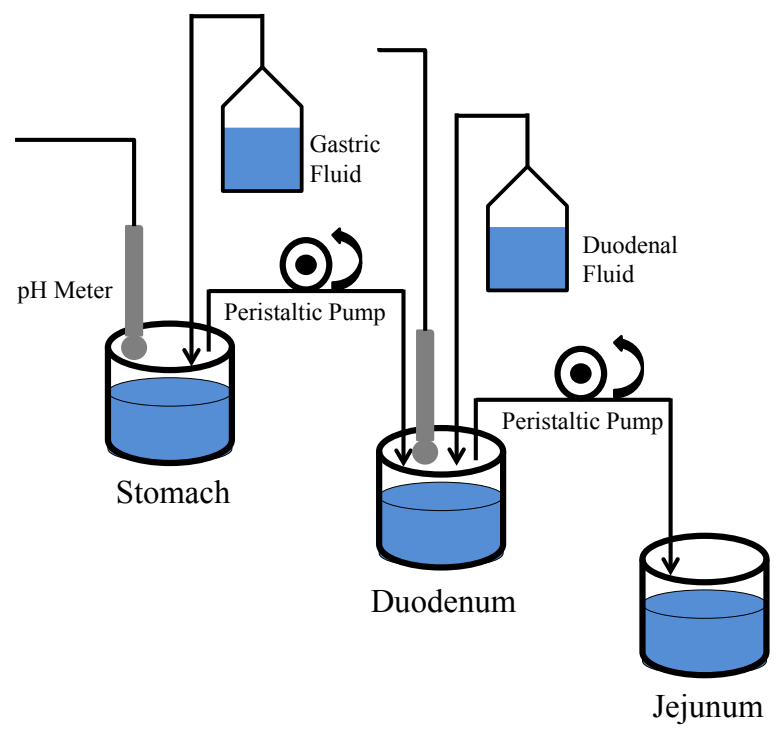

Figure 1: The diagram of the GIS

*Corresponding author: Tsume $\mathrm{Y}$, College of Pharmacy, The University of Michigan, 428 Church Street, Ann Arbor, Ml 48109-1065, Phone: 734-647-2345 Fax: 734-763-6423; E-mail: ytsume@umich.edu

Received May 27, 2013; Accepted September 23, 2013; Published September 30, 2013

Citation: Tsume Y, Amidon GL, Takeuchi S (2013) Dissolution Effect of Gastric and Intestinal pH fora BCS class II drug. Pioglitazone: New in vitro Dissolution System to Predict in vivo Dissolution. J Bioequiv Availab 5: 224-227. doi:10.4172 jbb.1000162

Copyright: ( 2013 Tsume Y, et al. This is an open-access article distributed under the terms of the Creative Commons Attribution License, which permits unrestricted use, distribution, and reproduction in any medium, provided the original author and source are credited. 
duodenum chambers have capacities of $50-300 \mathrm{~mL}$ and $50-125 \mathrm{~mL}$, respectively, and the fluid transit time between those chambers can be adjusted at the range of $1-40 \mathrm{~mL} /$ minute by peristaltic pumps based on the simulation design of the gastric emptying time and GI transit time. The jejunalchamber is only the reservoir from the duodenal chamber and will provide the important information of drug concentration to predict the oral drug absorption of test compound. Those settings can be modified depending on the physiological characteristics of the species.

\section{Preparation of dissolution media}

The following dissolution media were used; $0.01 \mathrm{~N} \mathrm{HCl}$ solution without enzymes ( $\mathrm{pH}$ 2) andUSP simulated intestinal fluid (SIF) without enzymes ( $\mathrm{pH}$ 6.5).

\section{Dissolution Study of pioglitazone with USP dissolution apparatus II}

Dissolution characteristics of a pioglitazone tablet were examined using the USP apparatus II (paddle), Hanson Research (Chatsworth, CA) Model SR6, Serial \# 0698-1166 was used for dissolution studies at a rotational speed of $50 \mathrm{rpm}$ at $37.0 \pm 0.5^{\circ} \mathrm{C}$ in $300 \mathrm{~mL}$ of the dissolution media; $50 \mathrm{mM}$ phosphate buffer (simulated intestinal fluid: SIF) ( $\mathrm{pH}$ 6.5). The test tablet was placed in the buffer media to start its dissolution study. Samples were drawn manually at 5, 10, 15, 20, 25, 30, 45, 60, 75, 90,120 , and 180 min and the same sample volume was replaced with the equal amount of blank medium tempered at $37^{\circ} \mathrm{C}$.All samples were immediately spun at 2,000 $\mathrm{x}$ g for 20 seconds and the supernatant was diluted with the equal volume of methanol for HPLC analysis.

\section{Dissolution study of pioglitazone with GIS}

In this experiment, $0.01 \mathrm{~N} \mathrm{HCl}$ solution $(\mathrm{pH} 2)$, and $50 \mathrm{mM}$ phosphate buffer (simulated intestinal fluid: SIF) ( $\mathrm{pH}$ 6.5) were used in each chamber. The initial volumes and pHsof the stomachand duodenum chambers were $300 \mathrm{~mL}$ at $\mathrm{pH}$ 2, representing $50 \mathrm{~mL}$ of stomach fluid plus $250 \mathrm{~mL}$ of dose volume, and $50 \mathrm{~mL}$ at $\mathrm{pH} 6.5$, respectively. The test tablet was placed in the stomach chamber to start the dissolution study with the GIS. Samples were taken at the specific time points from each chamber over 65 - 120minutes. The fluid was transferred at the range of 1-14 mL/minute to determine the dissolved drug concentration in each chamber. Those chambers were incubated at $37^{\circ} \mathrm{C}$ and $\mathrm{pH}$ changes were monitored by $\mathrm{pH}$ probes (Beckman Coulter, Brea, CA). Paddles were provided to mix fluid in each chamber. Fluid volume in duodenum was maintained at the constant volume. All samples were immediately spun at 2,000 $\mathrm{x} g$ for 20 secondsandthe supernatantwas diluted with the equal volume of methanol. The drug concentration was determined by HPLC analysis.

\section{Solubility studyof a pioglitazone tablet}

An excess amount of each drug, a pioglitazone tablet, was placed in $200 \mathrm{~mL}$ of each one of the following solutionsto determine the saturated solubility of this pioglitazone product: $3.125 \mathrm{mM}$ phosphate buffer containing $15.4 \mathrm{mMNaCl}, 6.25 \mathrm{mM}$ phosphate buffer containing $15.4 \mathrm{mMNaCl}, 12.5 \mathrm{mM}$ phosphate buffer containing $15.4 \mathrm{mMNaCl}, 25$ $\mathrm{mM}$ phosphate buffer containing $15.4 \mathrm{mMNaCl}$, and $50 \mathrm{mM}$ phosphate buffer containing $15.4 \mathrm{mMNaCl}(\mathrm{pH}$ 6.5). The flasks were incubated at $37^{\circ} \mathrm{C}$ and samples were collected every 45 minutes for $4 \mathrm{hrs}$. All samples were centrifuged at $12000 \mathrm{x} g$ for 3 minutes and the supernatant was diluted with the equal volume of methanol. The drug solubility was determined by HPLC analysis.
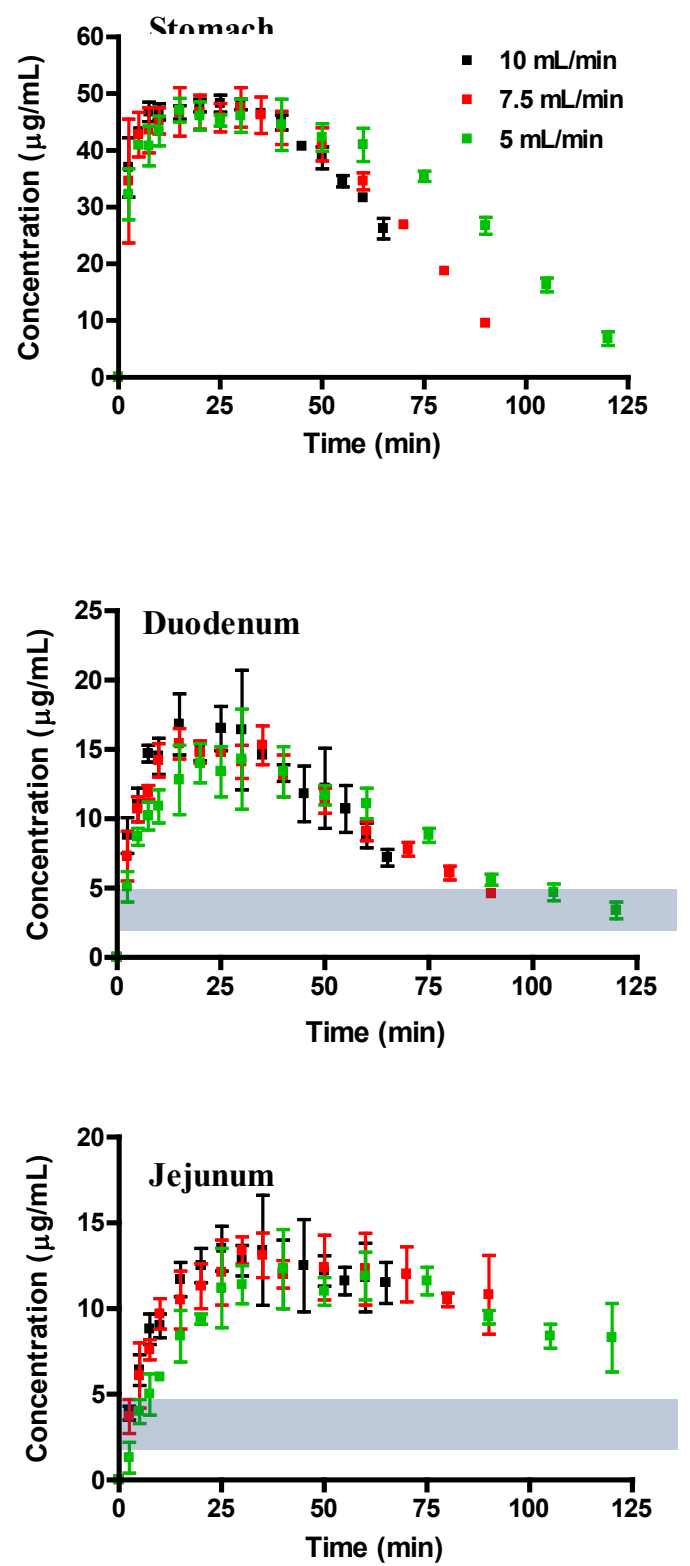

Figure 2: Dissolution profile of pioglitazone tablet in each compartment, stomach, duodenum, and jejunum.

Area ( ) represents the saturated concentration range of pioglitazone from the solubility tests. Values presented are the mean \pm S.D., $n=3$.

\section{HPLC Analysis}

The concentration of pioglitazone was determinedon a Waters HPLC system (Waters, Inc., Milford, MA). The HPLCsystem consisted of two Waters pumps (model 515), a Waters autosampler(WISP model 712), and a Waters UV detector (996 photodiode arraydetector) controlled by Waters Millennium ${ }^{\circledR} 32$ software (version 3.0.1). Samples were resolved in a Cadenza CD-C18 column $(3 \mu \mathrm{m}, 3 \times 100 \mu \mathrm{mm})$ equippedwith a guard column. The mobile phase consisted of $0.1 \%$ TFA/water (Solvent A) and 0.1\% TFA/acetonitrile (Solvent B) with the solvent B gradient changing from $25-45 \%$ at a rate of $6.7 \% /$ minute during a 10 minute run. Standard curve generated for pioglitazone was 
utilized for quantitation of integrated area under peaks. The detection wavelength was $269 \mathrm{~nm}$.

\section{Results}

In GIS, the dissolution of pioglitazone tablets with the initial transit time of $10 \mathrm{~mL} /$ minuteexhibited the highest pioglitazone concentration $(16.8 \pm 2.2 \mu \mathrm{g} / \mathrm{mL})$ in the duodenal chamber $(\mathrm{pH}$ 6.5). However, there is no significant difference in all dissolution profileswith the initial transit time of $5-10 \mathrm{~mL} /$ minute(Figure 2). The dissolution for a pioglitazone tablet in the USP dissolution apparatus II exhibited only $0.6 \%$ release (the range of concentration; $0.56 \pm 0.04$ $\mu \mathrm{g} / \mathrm{mL}$ ) over 3 hours in $50 \mathrm{mM}$ phosphate buffer ( $\mathrm{pH} 6.5$ ) (Figure 3). A pioglitazonetabletwas quicklydisintegrated and dissolved in the stomach chamber orin the USP vesselwithin 30 minutes regardless of transit timeand dissolution methodology. The solubility studies of apioglitazonetablet showed the solubility range of concentration $1.8-4.3 \mu \mathrm{g} / \mathrm{mL}$ in different buffer strength (Table 1 ). This solubility range of pioglitazone was applied to Figure 2 to indicate the possible pioglitazone concentration in 3.125 - $50 \mathrm{mM}$ phosphate buffer (pH6.5). The highest concentrations of pioglitazone in duodenal and jejunal chambers were $16.8 \mu \mathrm{g} / \mathrm{mL}$ and $13.5 \mu \mathrm{g} / \mathrm{mL}$, which were 7.5 -fold and 9.25 -fold higher than the concentration $(1.8 \mu \mathrm{g} / \mathrm{mL})$ obtained by the solubility tests of pioglitazone in $50 \mathrm{mM}$ phosphate buffer ( $\mathrm{pH}$ 6.5). On the other hand, the highest concentration of pioglitazone in the USP dissolution apparatus II was $0.6 \mu \mathrm{g} / \mathrm{mL}$, which was 3.0 -folder lower than the concentration obtained by the same tests.

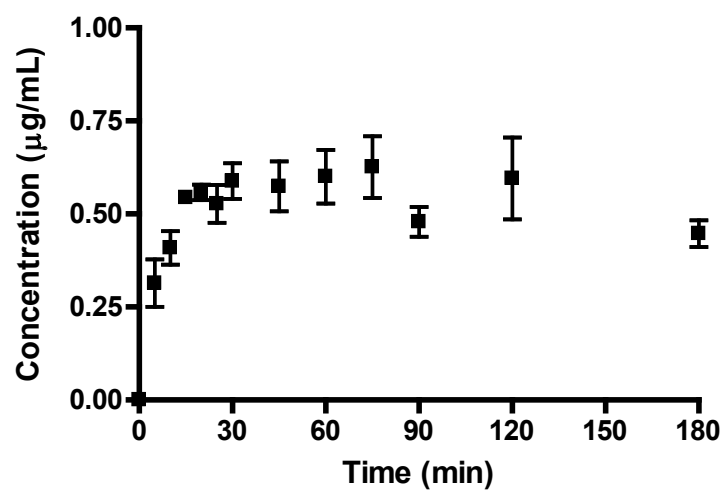

USP dissolution apparatus II with $300 \mathrm{~mL}$ of SIF $(\mathrm{pH} 6.5)$, paddle rotation set to $50 \mathrm{rpm}$. Values presented are the mean \pm S.D., $\mathrm{n}=3$

Figure 3: Dissolution profile of pioglitazone tablet in SIF (pH6.5) in the USP dissolution apparatus II.

\begin{tabular}{|l|l|}
\hline Phospate Conc. $(\mathbf{m M})$ & Tablet \\
\hline 3.125 & Pioglitazone Conc. $(\boldsymbol{\mu g} / \mathbf{m L})$ \\
\hline 6.25 & 4.25 \\
\hline 12.5 & 3.82 \\
\hline 25 & 4.27 \\
\hline 50 & 3.11 \\
\hline
\end{tabular}

The pioglitazone tablet was placed in $200 \mathrm{~mL}$ of various concentration of phosphate buffer $\left(\mathrm{pH} \mathrm{6.5)}\right.$. The flasks were incubated at $37^{\circ} \mathrm{C}$ for 4 hours. The concentration of pioglitazone was determined by HPLC analysis. Values presented are the $\operatorname{mean}(\mathrm{n}=3)$.

Table 1: The solubility study of pioglitazone in the different concentration of phosphate buffer ( $\mathrm{pH} 6.5)$.

\section{Discussion}

Weak base drugs like ketoconazole and carvedilol might exhibit bioequivalence (BE) using existing in vitro dissolution methods like UPS dissolutionapparatus II. However, the progression of in vivo dissolution will be far more complicated than the results of in vitro dissolution studies with USP dissolutionapparatus due to the $\mathrm{pH}$ changes in the GI tract causing the precipitation orthe supersaturation of those BCS class II drugs. Consequently, the in vitro dissolution results may not predictin vivo dissolution profile. This type of discrepancy between in vitrodissolution profilesand in vivodissolution results and, hence, in vivo drug absorption, especially for BCS class II and IV drugs, raises the questions regarding the current in vitro dissolution tests for bioequivalence.The gastro intestinal simulator (GIS) is the in vitro dissolution apparatus to understand the in vivo dissolution phenomena of those drugs. The buffer solution in each compartment of the GIS will be transferred from one chamber to the next chamber with various transit rates.

The duodenal and small-intestinal transit timesin the fasted state are approximately 0.5 hour and $3-4$ hours, respectively, and the gastric residence time is approximately 15 - 60 minutes[20-24].The measured $\mathrm{pH}$ of human intestine in the fasted state is reportedly the range of 5.5 to 7.5 in the duodenum and 6.2 to 6.7 in the proximal small intestine[25-27].Therefore, the middle of $\mathrm{pH}$ ( $\mathrm{pH}$ 6.5) was adopted for this set ofin vitro dissolution studies.ABCS class IIdrug product such as pioglitazone (pKa 5.8 and 6.4) would exhibit much lower solubility in the duodenam and jejunumin $\mathrm{pH} 6.5$ than one in gastric pHdue to its chemical characters. Therefore, the drug which has similar physicochemical characteristicto pioglitazonemay be completely dissolved in the stomach but may occurthe precipitation to inhibit its absorption or reach the supersaturationin small intestine to enhance its absorption.

The average volumes of human intestinal fluid in a fasted state are reportedly $184 \mathrm{~mL}$ for duodenum and $63 \mathrm{~mL}$ for jejunum [27]. With those volumes at the duodenum and jejunum in a fasted state and the solubility results in $50 \mathrm{mM}$ phosphate buffer, less than $2 \%$ ofpioglitazone(30 $\mathrm{mg}$ tablet) would be dissolved at those small intestinal segments at $\mathrm{pH}$ 6.5.The dissolution results of pioglitazone tablets in $50 \mathrm{mM}$ phosphate buffer( $\mathrm{pH}$ 6.5)with USP dissolution apparatus II displayedeven less drug dissolutionover 3 hours, implying the less absorption of pioglitazone at the small intestine. However, the dissolution results of pioglitazone with the GIS exhibited 3.1-to 9.2fold higher concentrationthan the obtained saturated concentration in duodenual and jejunal chambers, suggesting the supersaturation of piglitazone in the proximal small intestinal region. As a result, higher in vivo absorption of pioglitazone will be anticipated. It has been reported that the orally dosed pioglitazone is well absorbed and its oral bioavailabilityis $>80 \%[11,12]$. Less than $2 \%$ of in vitro dissolution profile may not explain well-absorbed oral dose of pioglitazone. This would be the discrepancy between current in vitro dissolution profiles and in vivo results.

The differences of the dissolution rate and solubility in between acidic $\mathrm{pH}$ and $\mathrm{pH} 6.5$ were significant for weak basic drugs and the solubility of pioglitazone would be largely lowered at $\mathrm{pH} 6.5$, which is closer to the one of $\mathrm{pKa}$ of pioglitazone. The dissolution rate of pioglitazone would be sensitive to the $\mathrm{pH}$ changes in the human intestine. This supersaturation phenomenon will not be observed in current dissolution systems like a USP apparatus II. As a result, it is extremely hard to predict in vivo dissolution. However, the GIS has the 
Citation: Tsume Y, Amidon GL, Takeuchi S (2013) Dissolution Effect of Gastric and Intestinal pH fora BCS class II drug, Pioglitazone: New in vitro Dissolution System to Predict in vivo Dissolution. J Bioequiv Availab 5: 224-227. doi:10.4172/jbb.1000162

capability to observe the supersaturation and, perhaps, precipitation and, hence, to predict better in vivo dissolution.

Buffer species and buffer capacity of dissolution medium along with buffer $\mathrm{pH}$ clearly have a significant effect on the dissolution rate for test drugs like ketoconazole and pioglitazone. Thus, the selection of dissolution media is crucial. It is likely that the concentration of phosphate buffer $(50 \mathrm{mM})$ is too high for BE studies and may not reflect in vivo dissolution media, which is mainly bicarbonate $[27,28]$. The in vitro dissolution rate is clearly dependent on the $\mathrm{pH}$, buffer species and buffer capacity of the medium for drugs products. The USP test does not reflect the human intestinal in vivo environment and may not suitable for in vitro dissolution study to predict in vivo dissolution and, hence, to evaluate bioequivalence. The GIS has the potential to be a standard biopredictive in vitro dissolution method for the better prediction of in vivo dissolution and, therefore, bioequivalence.

\section{References}

1. U.S. FDA Department of Health and Human Services (2000) Food and Drug Administration Center for Evaluation and Research., in Guidances for industry: Waiver of in vivo bioavailability and bioequivalence studies for immediaterelease solid oral dosage forms based on a Biopharmaceutics Classification System.

2. Verbeeck RK, Musuamba FT (2012) The revised EMA guideline for the investigation of bioequivalence for immediate release oral formulations with systemic action. J Pharm Pharm Sci 15: 376-388.

3. Tubic-Grozdanis M, Bolger MB, Langguth P (2008) Application of gastrointestinal simulation for extensions for biowaivers of highly permeable compounds. AAPS J 10: 213-226.

4. Avdeef A, Box KJ, Comer JE, Gilges M, Hadley M, et al. (1999) PH-metric $\log P$ 11. pKa determination of water-insoluble drugs in organic solvent-water mixtures. J Pharm Biomed Anal 20: 631-641.

5. Potthast $\mathrm{H}$, Dressman JB, Junginger HE, Midha KK, Oeser $\mathrm{H}$, et al. (2005) Biowaiver monographs for immediate release solid oral dosage forms: ibuprofen. J Pharm Sci 94: 2121-2131.

6. Yazdanian M, Briggs K, Jankovsky C, Hawi A (2004) The "high solubility" definition of the current FDA Guidance on Biopharmaceutical Classification System may be too strict for acidic drugs. Pharm Res 21: 293-299.

7. Alvarez C, Nunez I, Torrado JJ, Gordon J, Potthast H, et al. (2011) Investigation of the possibility of believers for ibuprofen. J Pharm Sci 100: 2343-2349.

8. Hsieh YL, llevbare GA, Van Eerdenbrugh B, Box KJ, Sanchez-Felix MV, et al. (2012) $\mathrm{pH}$-Induced precipitation behavior of weakly basic compounds: determination of extent and duration of supersaturation using potentiometric titration and correlation to solid state properties. Pharm Res. 29: 2738-2753.

9. Psachoulias D, Vertzoni M, Goumas K, Kalioras V, Beato S, et al. (2011) Precipitation in and supersaturation of contents of the upper small intestine after administration of two weak bases to fasted adults. Pharm Res 28: 31453158.

10. Carver PL, Berardi RR, Knapp MJ, Rider JM, Kauffman CA, et al. (1994) In vivo interaction of ketoconazole and sucralfate in healthy volunteers. Antimicrob Agents Chemother 38: 326-329.

11. Eckland DA , Danhof M (2000) Clinical pharmacokinetics of pioglitazone. Exp Clin Endocrinol Diabetes 108: S234-S242.
12. Kadam R, Bourne D, Kompella U, Aquilante C (2013) Effect of Cytochrome P450 2C8*3 on the Population Pharmacokinetics of Pioglitazone in Healthy Caucasian Volunteers. Biol Pharm Bull 36: 245-251.

13. Carino SR, Sperry DC, Hawley M (2006) Relative bioavailability estimation of carbamazepine crystal forms using an artificial stomach-duodenum model. J Pharm Sci 95: 116-125.

14. Carino SR, Sperry DC, Hawley M (2010) Relative bioavailability of three different solid forms of PNU-141659 as determined with the artificial stomachduodenum model. J Pharm Sci 99: 3923-3930.

15. Mudie DM, Shi Y, Ping H, Gao P, Amidon GL, et al. (2012) Mechanistic analysis of solute transport in an in vitro physiological two-phase dissolution apparatus. Biopharm Drug Dispos 33: 378-402.

16. Shi $Y$, Gao P, Gong Y, Ping H (2010) Application of a biphasic test for characterization of in vitro drug release of immediate release formulations of celecoxib and its relevance to in vivo absorption. Mol Pharm 7: 1458-1465.

17. Vatier J, Malikova-Sekera E, Vitre MT, Mignon M (1992) An artificial stomachduodenum model for the in-vitro evaluation of antacids. Aliment Pharmacol Ther 6: 447-458.

18. Vatier JL, Gao Z, Fu-Cheng XM, Vitre MT, Levy DA, et al. (1992) Evidence for the interaction between antacid and gastric mucosa using an "artificial stomach" model including gastric mucosa. J Pharmacol Exp Ther 263: 1206-1211.

19. Kaus LC, Fell JT (1984) Effect of stress on the gastric emptying of capsules. J Clin Hosp Pharm 9: 249-251.

20. KortejÃarvi H, Shawahna R, Koski A, Malkki J, Ojala K, et al. (2010) Very rapid dissolution is not needed to guarantee bioequivalence for biopharmaceutics classification system (BCS) I drugs. J Pharm Sci 99: 621-625.

21. Mudie DM, Amidon GL, Amidon GE (2010) Physiological parameters for oral delivery and in vitro testing. Mol Pharm 7: 1388-1405.

22. Oberle RL, Chen TS, Lloyd C, Barnett JL, Owyang C, et al. (1990) The influence of the interdigestive migrating myoelectric complex on the gastric emptying of liquids. Gastroenterology 99: 1275-1282.

23. Reddy SM, Sinha VR, Reddy DS (1999) Novel oral colon-specific drug delivery systems for pharmacotherapy of peptide and nonpeptide drugs. Drugs Today (Barc) 35: 537-580.

24. Ibekwe VC, Fadda HM, McConnell EL, Khela MK, Evans DF, et al. (2008) Interplay between intestinal $\mathrm{pH}$, transit time and feed status on the in vivo performance of $\mathrm{pH}$ responsive ileo-colonic release systems. Pharm Res 25 1828-1835.

25. Lee KJ, Vos R, Janssens J, Tack J (2004) Influence of duodenal acidification on the sensorimotor function of the proximal stomach in humans. Am J Physiol Gastrointest Liver Physiol 286: G278-284.

26. Perez de la Cruz Moreno M, Oth M, Deferme S, Lammert F, Tack J, et al. (2006) Characterization of fasted-state human intestinal fluids collected from duodenum and jejunum. J Pharm Pharmacol 58: 1079-1089.

27. Karr WG, Osler AW, Sample AB (1935) Intubation Studies of the Human Smal Intestine. IV. Chemical Characteristics of the Intestinal Contents in the Fasting State and as Influenced by the Administration of Acids, of Alkalies and of Water. J Clin Invest. 14: 893-900

28. Sheng JJ, McNamara DP, Amidon GL (2009) Toward an in vivo dissolution methodology: a comparison of phosphate and bicarbonate buffers. Mol Pharm 6: 29-39. 